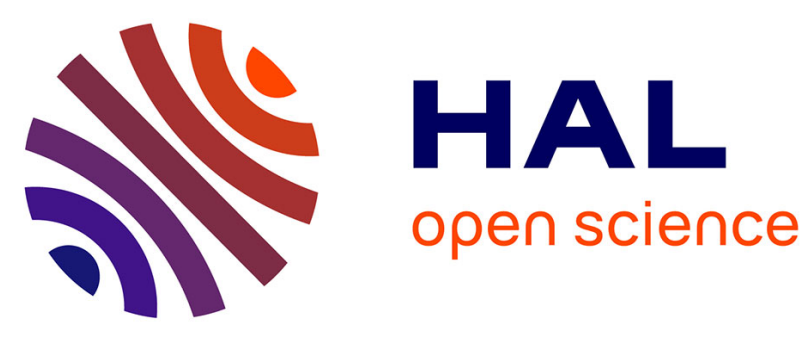

\title{
The effect of ankle and hindfoot malalignment on foot mechanics in patients suffering from post-traumatic ankle osteoarthritis
}

Paul André Deleu, Alexandre Naaim, Laurence Cheze, Raphaël Dumas, Bernhard Devos Bevernage, Laurent Goubau, Jean-Luc Besse, Thibaut Leemrijse

\section{To cite this version:}

Paul André Deleu, Alexandre Naaim, Laurence Cheze, Raphaël Dumas, Bernhard Devos Bevernage, et al.. The effect of ankle and hindfoot malalignment on foot mechanics in patients suffering from post-traumatic ankle osteoarthritis. Clinical Biomechanics, 2021, 81, 31p. 10.1016/j.clinbiomech.2020.105239 . hal-03124824

\section{HAL Id: hal-03124824 \\ https://hal.science/hal-03124824}

Submitted on 29 Jan 2021

HAL is a multi-disciplinary open access archive for the deposit and dissemination of scientific research documents, whether they are published or not. The documents may come from teaching and research institutions in France or abroad, or from public or private research centers.
L'archive ouverte pluridisciplinaire HAL, est destinée au dépôt et à la diffusion de documents scientifiques de niveau recherche, publiés ou non, émanant des établissements d'enseignement et de recherche français ou étrangers, des laboratoires publics ou privés. 


\section{Journal Pre-proof}

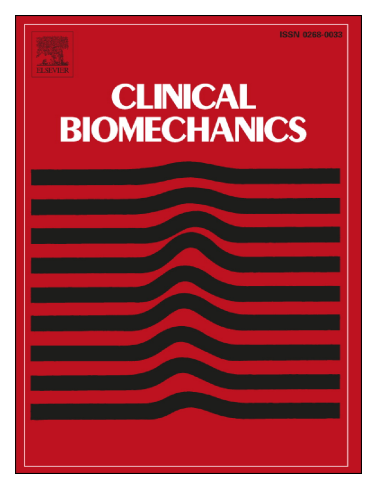

P.-A. Deleu, A. Naaim, L. Chèze, R. Dumas, B. Devos Bevernage,

L. Goubau, J.-L. Besse, T. Leemrijse

The effect of ankle and hindfoot malalignment on foot mechanics in patients suffering from post-traumatic ankle osteoarthritis

PII: $\quad$ S0268-0033(20)30358-2

DOI: $\quad$ https://doi.org/10.1016/j.clinbiomech.2020.105239

Reference: $\quad$ JCLB 105239

To appear in: $\quad$ Clinical Biomechanics

Received date: $\quad 29$ September 2019

Accepted date: $\quad 17$ November 2020

Please cite this article as: P.-A. Deleu, A. Naaim, L. Chèze, et al., The effect of ankle and hindfoot malalignment on foot mechanics in patients suffering from post-traumatic ankle osteoarthritis, Clinical Biomechanics (2020), https://doi.org/10.1016/ j.clinbiomech.2020.105239

This is a PDF file of an article that has undergone enhancements after acceptance, such as the addition of a cover page and metadata, and formatting for readability, but it is not yet the definitive version of record. This version will undergo additional copyediting, typesetting and review before it is published in its final form, but we are providing this version to give early visibility of the article. Please note that, during the production process, errors may be discovered which could affect the content, and all legal disclaimers that apply to the journal pertain.

(C) 2020 Published by Elsevier. 


\title{
The effect of ankle and hindfoot malalignment on foot mechanics in
} patients suffering from post-traumatic ankle osteoarthritis

\author{
P-A. Deleu ${ }^{1,2}$, A. Naaim ${ }^{1}$, L. Chèze ${ }^{1}$, R. Dumas ${ }^{1}$, B. Devos Bevernage ${ }^{2}$, L. Goubau ${ }^{2}$, J-L \\ Besse $^{3}$, T. Leemrijse ${ }^{2}$
}
${ }^{1}$ Univ Lyon, Université Claude Bernard Lyon 1, Univ Gustave Eiffel, IFSTTAR, LBMC UMR_T9406, F69622, Lyon, France
${ }^{2}$ Foot \& Ankle Institute, Brussels, $F$ ely $\cdot 1 m$
${ }^{3}$ Hospices Civils de Lyon, Centre Hospitalier Lyon-Sud, S、 vice de Chirurgie Orthopédique et
Traumatologique, $\mathrm{F} \cdot$ nce
Email: pa.deleu $\approx$ z nail.com

\section{Full contact details}

Paul-André Deleu (Correspondi ing a 'thor)

Foot \& Ankle Institute

Avenue Ariane 5

1200 Brussels

Belgium

Email: pa.deleu@gmail.com

Word count

- Abstract: 247words

- Main text: 3538 words 


\section{ABSTRACT}

Background: Ankle and hindfoot malalignment is a common finding in patients suffering from post-traumatic ankle osteoarthritis. However, no studies have addressed the effect of concomitant foot deformities on intrinsic foot kinematics and kinetics. Therefore, the objective of this study was to investigate the effect of ankle and hindfoot malalignment on the kinematics and kinetics of multiple joints in the foot and ankle complex in patients suffering from post-traumatic ankle osteoarthritis.

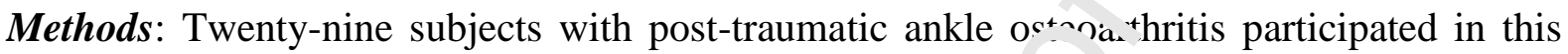
study. Standardized weight-bearing radiographs were $\mathrm{ob}^{\prime} \mathrm{dl}{ }^{\prime} \mathrm{d}$ preoperatively to categorize patients as having cavus, planus or neutral ankle and $h_{1 \mathbf{h}}{ }^{\mathrm{d}}$ foot alignment, based on $4 \mathrm{X}$-ray measurements. All patients underwent standard gait 'ssu 'sment. A 4-segment foot model was used to estimate intrinsic foot joint kinematic: $a_{2}$ d '.inetics during gait. Statistical parametric mapping was used to compare foot kine ${ }^{\prime} \cdot{ }^{\prime}{ }^{\circ}$ is and kinetics between groups.

Findings: There were 3 key findings r $u$ arding overall foot function in the 3 groups of posttraumatic ankle osteoarthritis: (i) $\sim$ te $\bullet \bullet$ frontal and transverse plane inter-segmental angles and moments of the Shank-Cai aneus and Calcaneus-Midfoot joints in the cavus compared to the planus group; (ii) in ca $\cdots$, OA group, Midfoot-Metatarsus joint abduction sought to compensate the varus 11 - lunation of the ankle joint; (iii) there were no significant differences in inter-segmental angles and moments between the planus and neutral OA groups.

Interpretation: Future studies should integrate assessment of concomitant foot and ankle deformities in post-traumatic ankle osteoarthritis, to provide additional insight into associated mechanical deficits and compensation mechanisms during gait.

Keywords: ankle osteoarthritis, malalignment, foot kinetics, kinematics, gait 


\section{Introduction}

There is now a growing body of evidence for significant biomechanical impairment of the entire foot and lower limb in patients suffering from ankle osteoarthritis. ${ }^{1,28,34}$ Gait is asymmetric and characterized by decreased walking speed, stride length and ankle joint complex range of motion. ${ }^{38}$ Patients also seem to adopt an analgesic walking strategy to prevent shear loading through the painful joint. ${ }^{38}$ Changes in joint mechanics are not restricted to the painful ankle joint, but also affect hip mechanics, especially during the pushoff phase of gait. $^{8,34}$ Compensatory increases in hip flexion mor ent and in hip extension were reported in patients with ankle osteoarthritis, to cope $w_{1} .7$ the decrease in plantarflexion moment resulting from reduced peak ankle plantar flevinı during terminal stance. ${ }^{37} 3 \mathrm{D}$ multisegment kinematic foot models also revealed redur ed ?nge of motion in the intrinsic foot joints in patients suffering from ankle osteoa th. ${ }^{+}+{ }_{i}$, compared to healthy reference data. ${ }^{19,27}$ However, further insight into the compl $\sim r$ shavior of the foot and ankle during walking also requires analysis of power output. ${ }^{7,1-35,36}$ Recently developed 3D multi-segmental kinetic foot models were created to provide $"$.h estimations ${ }^{7,13,36}$ and were clinically interpreted in an accessible format through $\mathrm{i}$ e use of the 3D angular relationships between joint moment and joint angular velocity e itors. ${ }^{7}$ These models are still only exploratory, but their importance should not ' $\mathrm{c}$ underestimated as they showed altered inter-segmental moments and power in the distal foot joints of the affected side in patients suffering from ankle osteoarthritis. $^{13,35}$ However, published kinematic and kinetic studies tend to lack characterization of the ankle osteoarthritis, ${ }^{8}$ making the functional consequences difficult to determine without considering the morphological and structural changes associated with the ankle osteoarthritis.

End-stage ankle osteoarthritis rarely occurs in isolation, but more often presents concomitant ankle and hindfoot deformities. ${ }^{24}$ As the ankle is a weight-bearing joint, the 
intra-articular load distribution is not only influenced by the alignment of the tibiotalar joint itself but is also highly dependent on extra-articular mechanical forces related to the 3D orientation of the distal joints of the affected ankle. ${ }^{20}$ However, these key factors and the corresponding changes in foot biomechanics have never been truly investigated. While the link is still unclear, the past literature stressed that, in order to systematically study foot and ankle pathology, objective measures of foot structure and intrinsic foot joint dynamics, sensitive to different foot morphotypes, are needed. ${ }^{6,25,31}$ Previous studies demonstrated that foot posture (e.g., cavus, planus) influences foot and lower limb s.nuscle activity ${ }^{31}$ and joint kinematics $^{5}$ and kinetics ${ }^{36}$ during gait. For example, ankl $\approx$ a. 1 midfoot power generation in children with pes planovalgus was respectively $38 \%$ and $37 \%$ lower than in control subjects. ${ }^{36}$ This means that functional consequences are difficult to determine without taking account of the morphological and structural $\mathrm{ch} \mathrm{ar}_{\mathrm{c}}{ }^{\mathrm{er}}$ associated with the ankle osteoarthritis.

The present study therefore ain d to investigate the interrelationship between osteoarticular foot deformities and chaı res in foot mechanics during gait in patients suffering from post-traumatic ankle osteoarthri ic. A cohort of subjects suffering from end-stage posttraumatic ankle osteoarthritis , 'as broken down into three deformity groups: neutral, planus and cavus. It is believed tha: .nkle osteoarthritis may lead to altered mechanical load and maladaptive motion 1s tuot joints other than the affected ankle joint. Therefore, our hypothesis was that the kinematic and kinetic curves of the intrinsic foot joints would differ between the three deformity groups, particularly in the transverse and frontal planes. Previous studies analyzing ankle osteoarthritis tested their hypotheses on a relatively small number of so-called summary metrics (e.g., peak values or range of motion values during sub-phases of the stance phase). ${ }^{19,35,38}$ These data-reduction techniques are computationally convenient, but may lead to opposing results or fragmented knowledge, impeding in-depth insight into compensation in the joints distal to the affected ankle joint. ${ }^{32}$ However, $1 \mathrm{D}$ statistical 
parametric mapping (SPM), was able to unravel the kinematic and dynamic differences between the deformity groups. This is of interest for clinicians analyzing the pathomechanics of ankle osteoarthritis. Furthermore, as the deformity is 3-dimensional, affects several joints and impacts gait dynamics and energetics as a whole, all the inter-segmental kinematics, moments around the three joint axes and the power variables were analyzed for the ShankCalcaneus, Calcaneus-Midfoot, Midfoot-Metatarsus, and 1st Metatarso-Phalangeal joints.

\section{Methods}

\subsection{Participants}

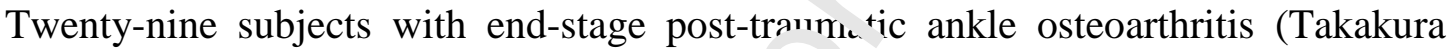
stage 3 to 4 (4 being complete obliteration of the i sin space)) scheduled for primary total ankle replacement or ankle fusion between Jinu rr 2017 and June 2019 participated in this study (Table 1). This study was approvt. ${ }^{1} b$, the local review board (B200-2017-061) and all participants signed an informed consu nt form. All patients suffered from end-stage posttraumatic ankle osteoarthritis secrnda $:$ to ankle-related fracture (post-fracture) or to chronic ankle instability (post-sprain) (Taule 1). Exclusion criteria were (1) age <18 years, (2) systemic or neurological $\lambda_{1} s^{\cdots} \mathrm{se}$, and (3) any medical problem other than post-traumatic ankle osteoarthritis liab: 10 affect gait. Standardized weight-bearing radiographs of the foot and the ankle were obtained preoperatively to assess the concomitant foot and ankle deformities and categorize them in three deformity groups. Cavus type (hereafter referred as cavus OA) was defined as: varus position of the hindfoot and ankle joint complex, bony dorsum deformity of the midfoot characterized by dorsiflexion of the talus within the ankle, upward position of the metatarsals with respect to the ground, and high medial longitudinal arch (Figure 1 A,B,C). Planus type (hereafter referred as planus OA) was defined as: valgus position of the hindfoot and ankle joint complex, collapse deformity of the midfoot 
characterized by a plantar flexion of the talus within the ankle, downward position of the metatarsals with respect to the ground, and low medial longitudinal arch (Figure 1 D,E,F). Subjects were allocated to the cavus or planus deformity group if they had 3 to 5 of these features with at least one deformity $\geq 10^{\circ}$. Neutral type ((hereafter referred as neutral OA) had no midfoot, hindfoot or ankle malalignment. Osteoarthritis severity was scored on the Canadian Orthopaedic Foot \& Ankle Society (COFAS) classification system (Table 1$)^{24}$ : Type 1, isolated ankle osteoarthritis; Type 2, ankle osteoarthritis associated with intraarticular ankle deformity or tight heel cord or both; Typ 3 , ankle osteoarthritis with deformity of the hindfoot, midfoot, tibia or forefoot; and ' $y$ p 4, Type 1 to 3 with subtalar or calcaneocuboid or talonavicular osteoarthritis. $^{24}$

\subsection{Radiographic assessment}

Radiographic assessment comp « : (1) standardized anteroposterior ankle Méary view to measure the hindfoot deformı: $\left(\gamma\right.$ angle: $<90^{\circ}=$ valgus; $>90^{\circ}=$ varus $)$ and intraarticular ankle varus or valgus $\because n^{-1} \mathrm{or}_{\mathbf{L}^{2}}{ }^{2}$ ent (Tibia-Talus) $\left(\alpha\right.$ angle: $\angle 90^{\circ}=$ valgus; $>90^{\circ}=$ varus) ${ }^{24,30}$ (2) standardized $w$ ight-bearing lateral foot (and ankle) view to measure the midfoot deformity as the $\sim^{1} a_{1},{ }^{\prime \prime}$ it metatarsal angle $\left(\geq 10^{\circ}\right)^{24}\left(\beta 1\right.$ angle: $\leq 170^{\circ}=$ bony dorsum deformity; $\geq 190^{\circ}=$ colı sse deformity) and the medial longitudinal arch deformity as DjianAnnonier angle $\left(\geq 10^{\circ}\right)\left(\beta 2\right.$ angle: $\leq 115^{\circ}=$ high arch; $\geq 130^{\circ}=$ low arch $)($ Figure 1$) .{ }^{10}$

\subsection{Data collection}

In the measurement session, patients walked at self-selected speed over a $10 \mathrm{~m}$ walkway in which an AMTI (Advanced Mechanical Technology, Inc., Watertown, MA, USA) with embedded force plate and Footscan® pressure plate $(0.58 \mathrm{~m}$ x $0.42 \mathrm{~m} ; 4,096$ sensors, 2.8 sensors per $\mathrm{cm}^{2}$; RsScan International, Paal, Belgium). The force plate was 
custom-made to fit the dimensions of the pressure plate. This set-up provided continuous calibration of the pressure plate with respect to the force plate, using an RsScan ${ }^{\circledR}$ 3D box. Sixteen $8 \mathrm{~mm}$ retro-reflective markers were placed on the foot and shank of each participant, according to the multi-segment Rizzoli foot model. ${ }^{26}$ To record kinematic data during walking over the walkway, a passive optoelectronic motion analysis system (Qualysis, Göteborg Sweden) consisting of 8 Miqus cameras was used, sampling at $200 \mathrm{~Hz}$. All marker trajectories were computed by Qualysis Tracking Manager 2.16 (Qualysis, Göteborg Sweden). Integration and synchronization of the 3 hardware drvicis used a Miqus Sync unit interface (Qualysis, Göteborg Sweden). Technical infe ^mı tion about synchronization is provided in Supplementary Material. Data from the frret and pressure plates were measured at a sampling rate of $200 \mathrm{~Hz}$. Five representative tri $\cdot$ ls 'ere collected per participant. A trial was considered representative when the foot if : itf iest made clear contact with the pressure plate without visual adjustment in step,$\urcorner \eta$, h or step frequency to aim at the pressure plate. Walking speed was required to be simı $r$ across all trials in a given recording session.

\subsection{Data analysis}

Inter-segment center det. ${ }^{-i+}$ ons of the 4-segment foot model were based on an adapted version of Rizzoli's IT) multi-segment foot model, developed by Deschamps et al. (2017)(IOR-4Segment-model 1) (Figure 2). ${ }^{9}$ The main differences between IOR-4Segmentmodel $1^{9}$ and Rizzoli 's foot model $^{26}$ consists in the creation of a virtual cuboid marker (FCub) at two-thirds of the distal distance between the peroneal tubercle (FPT) and the base of the fifth metatarsal (FMT), and in the definition of the Calcaneus-Midfoot joint center (ID). Inter-segment 3D rotations were computed according to Deschamps et al.'s IOR4Segment-model 1 (2017), following ISB recommendations ${ }^{9}$, and were defined as follows: Shank-Calcaneus joint (midpoint between the malleoli markers, describing the shank- 
calcaneus center), Calcaneus-Midfoot joint (midpoint between the cuboid (FCub) and the navicular bone (FNT), describing the calcaneus-midfoot center), Midfoot-Metatarsus joint (at the second metatarsal base (SMB), describing the midfoot-metatarsus center), and $1^{\text {st }}$ Metatarso-Phalangeal joint (projection of $1^{\text {st }}$ metatarsal head marker (FM1) vertically at mid distance to the ground, describing the metatarsus-hallux center).

Inter-segmental forces $(\mathbf{F})$ and moments $(\mathbf{M})$ were computed in the inertial coordinate system by a bottom-up inverse dynamic method using a Newton-Euler recursive algorithm based on a homogeneous matrix formalism during the stance ${ }_{\mathbf{1}}^{\text {hhas }}$ of gait. ${ }^{29}$ Kinematic and force data were filtered using a low-pass zero-lag $4^{\text {th }}$ orde' $\mathbf{B u}$ 'terworth filter, with $10 \mathrm{~Hz}$ cutoff frequency. Inertia and weight parameters of oqu foot segment were neglected, considering that inertia effects during stance are negl' $g_{1} \iota^{\prime} \mathrm{e}$ compared to external forces. ${ }^{35}$ The force plate data were distributed over each $f \varkappa$ s gment using a validated proportionality scheme. $^{14,36}$ The subarea of each foo. $s f$ gment was estimated for each time frame by projecting the markers' position vertic a. $^{11} \mathrm{~V}$ on the sensor matrix of the pressure platform. The center of pressure $(\mathrm{CoP})$ of eact $\mathrm{se}_{\varepsilon}{ }^{-n}$.ent was calculated as the barycenter of all sensors allocated to the segment, basec in the pressure values measured in each sensor. The resulting $\mathrm{CoP}$ of each estimated suhan was then used as the $\mathrm{CoP}$ for the corresponding foot segment in inverse dynamics clculations. The inter-segmental moments were expressed in the proximal segment coordinate system. For energetics, in supplement to the joint power, the 3D angle $\alpha_{\mathrm{M} \omega}$ between the inter-segmental moment $(\mathbf{M})$ and the inter-segmental angular velocity ( $\omega)$ vectors was calculated as described by Dumas and Chèze (2008). ${ }^{12}$ When the $3 \mathrm{D}$ angle $\alpha_{\mathrm{M} \omega}$ is $<60^{\circ}$ or $>120^{\circ}$, the moment mainly drives the joint, with, respectively, propulsion or resistance; when it is between $60^{\circ}$ and $120^{\circ}$, the moment mainly stabilizes the joint (additional information in Supplementary Material). ${ }^{12}$ Inter-segmental kinematic and kinetic computations and extraction of discrete spatio-temporal variables (walking speed and stride 
length) were performed using an in-house Matlab@ program (The Mathworks Inc., Natick, MA, USA). Internal joint moments and powers were normalized by subject-mass and all 1D data were time-normalized to $100 \%$ of the stance phase. One-dimensional 3D inter-segmental kinematics, moments and power variables around the axes of the following inter-segmental joints were extracted to assess the differences between the three deformity groups: ShankCalcaneus joint, Calcaneus-Midfoot joint, Midfoot-Metatarsus joint, and $1^{\text {st }}$ MetatarsoPhalangeal joint.

\subsection{Statistical analysis}

First, the Shapiro-Wilk test was used to check $r_{-2}$. ormality. One-way ANOVA and Kruskal-Wallis test were used to identify signi ica $^{+}$differences between groups for demographic, spatio-temporal and radiogr: $\mathrm{ph}_{\mathbf{}_{2}}$ - variables. For significant differences, Gabriel's post-hoc test or the Mann-W. it ey-U test (adjusted $P$-value $(0.5 / 3=0.017)$ were used to indicate which groups were di ${ }^{\text {f }}$ erent. All statistical tests were conducted on SPSS software (version 25, IBM Corp, C'ricioo, USA).

One-dimensional statistica. parametric mapping (SPM) was used to compare foot kinematics and kineticr $\iota:$ ween groups, using an open-source code (v.M.0.4.5; www.spm1d.org) in M. $\mathrm{M}_{\mathbf{c}} \mathrm{lab} \subset$ (The Mathworks Inc., Natick, MA, USA). ${ }^{5,16}$ The main advantages of this methodological approach is that SPM regards the whole time-series as the unit of observation and that time-dependence is incorporated directly in statistical testing. 1D-SPM 1-way ANOVA over the normalized time series was used to confirm significant differences between groups. If statistical significance was reached, a post-hoc 1D-SPM 2sample t-test (post-hoc $P$-value $0.05 / 3=0.017$ ) was used to determine between which groups the significant differences occurred. Conceptually, for example, an SPM post-hoc 2-sample ttest is similar to the calculation and interpretation of a scalar post-hoc 2-sample t-test at each 
instant of time.

\section{Results}

\subsection{Demographic, spatiotemporal and radiographic data}

No inter-group differences were found for the demographic and spatio-temporal variables (Table 1). Significant differences were found between the cavus and planus OA groups for all radiographic parameters. The cavus OA group also showed sl $\mathrm{S}_{\mathrm{O}}$ nificantly greater medial longitudinal arch deformation than the neutral OA gro’.p. Méary angle was significantly different on all between-groups comparisons.

\subsection{SPM analysis}

There were significant SPM $\{F\}$ mai. ef .ects between the three groups for all the intrinsic foot joints.

\subsubsection{Planus $\mathrm{OA}$ versus neutra' $\mathrm{O}$}

Post-hoc comparisons shov ed no differences between planus and neutral OA groups for any foot inter-segmental ang: ${ }^{2}$ or moments. However, 1D-analysis revealed that the planus OA group exhibited a g. aater Shank-Calcaneus power pattern ( $p=0.016$; range: $93-94 \%$ of the stance phase) at end of stance phase than the neutral OA group.

\subsubsection{Cavus OA versus neutral OA}

The cavus OA group showed a more inverted angle of the Shank-Calcaneus joint $(p=0.017,0-6 \% \& \mathrm{p}<0.001$, range: $10-72 \%$ of the stance phase) associated with a more abducted angle of the Midfoot-Metatarsus joint ( $p<0.001$; range: $0-100 \%$ of the stance phase) than the neutral OA group during almost the entire stance phase. The $1^{\text {st }}$ Metatarso- 
Phalangeal joint showed greater dorsiflexion ( $\mathrm{p}=0.013$; range: $40-50 \%$ of the stance phase) in the cavus than in the neutral OA group during midstance. Post-hoc comparisons showed no differences in kinetics between these two groups.

\subsubsection{Cavus OA versus planus $\mathrm{OA}$}

The main differences observed between the planus and cavus OA groups all concerned the frontal and transverse plane (Figure 3-4). The planus OA group showed a significantly more everted Shank-Calcaneus angle $(p<0.001 ;$ raıge: $0-77 \%$ of the stance phase) associated with a more abducted Calcaneus-Midfo $\pi$ a. $\operatorname{~gle~}(p<0.001$; range: $0-94 \%$ of the stance phase) than the cavus OA group. The moment $r$ ttterns revealed that the planus OA group exhibited larger Shank-Calcaneus inversion r.101. ant $(p<0.001$; range: $10-35 \%$ of the stance phase) than the cavus OA group (Figt ie 1$)$ During propulsion, the cavus OA group showed larger Shank-Calcaneus abduci. $\urcorner$ moment $(p<0.001$; range: $88-95 \%$ of the stance phase) than the planus OA group. Hov aver, no differences were observed for power or 3D $\alpha_{\mathrm{M} \omega}$ angle patterns between the cr $\cdots \mathrm{s} \cdots \mathrm{d}$ planus OA groups.

\section{Discussion}

To our knowledge, $\therefore$ is was the first study to investigate the effect of ankle and hindfoot malalignment on the intrinsic foot mechanics in patients suffering from post-traumatic ankle osteoarthritis. Results showed that the cavus OA group presented a distinctive pattern of inter-segmental angles and moments compared to the neutral and planus OA groups. These differences shed light on a number of radiographic concepts which are currently used regarding the compensatory mechanism of the neighboring joints of the ankle, and in particular in the surgical management of intra- and extra-articular deformities in ankle osteoarthritis. 
Concerning 3D inter-segmental rotations and actions, the most important differences were observed between the cavus and planus OA groups in the shank-calcaneus and CalcaneusMidfoot joints during almost the entire stance phase. Our data seem to provide further evidence of the interrelationship between foot structure and alterations in foot mechanics. The cavus OA group showed a significantly greater inverted Shank-Calcaneus angle and a more adducted Calcaneus-Midfoot angle than the planus OA group. It is further believed that the etiology of these differences is mainly guided by the multiplanar orientation of the talus, guided in turn by the geometry of the subtalar joint. ${ }^{17}$ Radiommin: and anatomical cadaver studies suggested that pes cavus feet have a high vertical ub var joint axis associated with a talar head placed tightly within a subtalar joint gen m try featuring a V-shaped groove,

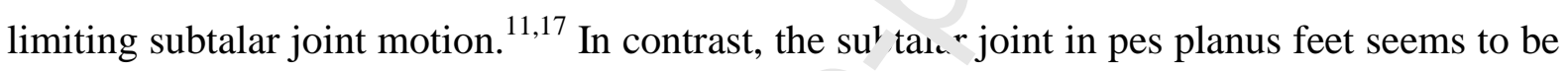
characterized by a lower vertical axis assoria. ${ }^{2}$ with larger and relatively flat articular facets, allowing greater range of motic $i \cdot$ the subtalar joint. ${ }^{2,17}$ This notion of talar head stability provided by the orientation $\iota^{c}$ the axis and the subtalar joint geometry is further underpinned by the 3D $\alpha_{\mathrm{M} \omega}$ ans, $\mathrm{c}^{\mathrm{c}}$. he Shank-Calcaneus and Calcaneus-Midfoot joints. Even though, with the numbe available, no significant difference could be demonstrated here, it could be observe - fru..1 the 3D $\alpha_{\mathrm{M} \omega}$ angle waveforms that both joints in the planus OA group adapted a moı resistant configuration than in the cavus OA group (Figure 5). This could mean that the planus OA group has to counter higher external forces than the cavus OA group, to keep the foot from collapsing and to stabilize it during walking.

Another noteworthy finding in our study was the significant difference in intersegmental angles between the cavus and the neutral OA groups. As expected, the cavus OA group showed a more inverted angle of the Shank-Calcaneus joint than the neutral OA group during a significant part of the stance phase. Similar shifts in Shank-Calcaneus kinematics were observed in previous studies highlighting differences in segmental foot kinematics 
between rectus, planus and cavus feet. ${ }^{5,25}$ A study analyzing segmental foot kinematic differences between foot types reported a shift in forefoot kinematics toward adduction in cavus foot compared to a neutral group in a sample of asymptomatic healthy adults. ${ }^{25}$ Therefore, considering the kinematic coupling between foot segments, it might be expected that cavus OA would exhibit greater Midfoot-Metatarsus joint adduction in association with the inverted position of the Shank-Calcaneus joint compared to neutral OA; in pint of fact, however, a significantly more abducted position was found in the Midfoot-Metatarsus joint. This 'twist" in the osteo-articular geometry of foot may represnt a zompensatory mechanism to counter the varus inclination of the ankle joint $\mathrm{a}^{\mathrm{a}} \mathrm{d}$ herefore to reduce the stress concentration located in the medial part of the joint. This i ind of osteo-articular configuration of the hindfoot and ankle joint complex has often ber, n I ferred as the "zig-zag" deformity, as the subtalar joint goes in the opposite directic $1 \ldots{ }^{1}$ ee tibiotalar deformity (Figure 1.F). ${ }^{16,21,23}$ Paradoxical shifts in load were reportec hy Knupp et al. (2011), with medial shifts in ankles with valgus deformity and lateral shifts : $\eta$ varus deformity. ${ }^{22}$

The positioning of the $1^{\text {st }}$ Netatarso-Phalangeal joint was also found to be significantly different, as the c. vus OA group showed less hallux plantar flexion with respect to the forefoot than the neiltı: JA group. This reduced plantar flexion of the $1^{\text {st }}$ MetatarsoPhalangeal joint may s duce loading underneath the hallux during the stance phase. This finding is supported by comparable studies analyzing kinematic and plantar pressure measurements between normal, planus and cavus feet. ${ }^{3,4}$

The majority of the significant differences were found in the cavus group versus both the neutral and planus groups. In contrast, no significant differences in inter-segmental angles or moments were observed between the planus and neutral groups. This suggests that the present results may be attributed to these two pathologic groups adopting a similar walking pattern to avoid pain in their arthritic ankle. Inspection of between-group comparisons found 
that the cavus OA group had significantly greater radiographic deformities than the neutral and planus OA groups. Only one variable differed significantly between the planus and neutral OA groups. This could mean that the difference in malalignment of the ankle and hindfoot between these two groups was not sufficiently great to be detected dynamically during gait.

The findings of this study should be considered in the context of two limitations. First, our classification of multi-joint, multi-planar foot deformities was based on 2D plain weight-bearing radiographs. Assessment of submalleolar deformit, is challenging, due to the limited imaging modalities. New-generation weight-beari $\mathrm{g}$ $\urcorner \mathrm{l}$ scans may be a valuable tool to better represent the 3D orientation of the hindf $n$ nt and ankle malalignment in ankle osteoarthritis. Moreover, partitioning of the total gi 'ind reaction forces acting on the calcaneus segment was based on an estimiti n nethod (proportionality scheme) which combined pressure and force plate data ${ }^{+} \mathrm{O}_{2}$,ether with marker placement data. Even though this proportionality scheme was valida: ${ }^{\circ}$, the reported ankle inter-segmental moments and powers should be regarded as estima. ${ }^{\circ}$. A second limitation was the use of skin markers to estimate joint centers and $\operatorname{seg}_{\mathbf{L}_{\mathbf{L}}}$ ent kinematics. Soft-tissue artefacts have been reported to be as much as 3-4 mm on the su ${ }^{-f}$,ce of the foot. ${ }^{18}$ The impact of these errors on the estimation of the moments and pov ars is currently difficult to estimate.

\section{CONCLUSION}

Three key findings in overall foot function were observed between three groups of post-traumatic ankle osteoarthritis: (i) altered frontal and transverse plane inter-segmental angles and moments of the Shank-Calcaneus and Calcaneus-Midfoot joints in the cavus OA group compared to the planus OA group; (ii) the cavus ankle group, Midfoot-Metatarsus joint abduction tried to reduce the varus inclination of the ankle joint; and (iii) there were no 
significant differences in inter-segmental angles or moments between the planus OA group and the neutral OA group. These findings indicate that malalignment of the hindfoot and the ankle as revealed by radiographic assessment does indeed influence foot mechanics during gait in patients suffering from post-traumatic ankle osteoarthritis.

\section{CONTRIBUTIONS}

PAD and TL were responsible for the conception and design of the research, reviewing articles, analyzing data, interpreting the results, writing and ${ }{ }_{r a}{ }^{c}$ ting the manuscript, and approving the final version of the manuscript. AN and I c v'ere responsible for conception and design of the review, reviewing articles, draftins c citically appraising and revising the manuscript for intellectual content. JLB, RD, LS and BDB were responsible for the conception and design of the review, dra itı $\sigma$ critically appraising and revising the manuscript for intellectual content. All a $\mathrm{u}^{\prime}$ nors read and approved the final version of the manuscript.

\section{COMPETING INTEREST S" "AT EMENT}

The authors do not have anv inalificant conflicts of interest relevant to this manuscript.

\section{ROLE OF THE FUNDING SOURCE}

This study was funded in part by a clinical research Grant from the Belgische Vereniging voor Orthopedie en Traumatologie (BVOT). Sponsor had no involvement in this article. 


\section{FIGURE LEGENDS}

Table 1: Demographic, spatio-temporal and radiographic data for the three patient groups: post-traumatic ankle osteoarthritis associated with planus foot deformity (Planus OA), with cavus foot deformity (Cavus OA), and without foot deformity (Neutral OA). Abbreviations: COFAS: Canadian Orthopaedic Foot \& Ankle Society classification system for ankle osteoarthritis; MLA: medial longitudinal arch; SD: standard deviation; BMI: body mass index; N/A: not applicable; N.S.: not significant. Statistics: $\mathrm{D}$ net 1 ling on the distribution of the demographic and spatio-temporal data, 1-way ANOV/^ (1 rmal distribution) ${ }^{\mathrm{a}}$ or KruskalWallis test (non-normal distribution) ${ }^{\mathrm{b}}$ was used to nss, ss statistical differences for each variable between the three groups. ${ }^{\mathrm{c}} X^{2}$ Extended Chi- ruare test ; *Gabriel's post-hoc test (adjusted $P$-value $0.3 / 3=0.017$ ); ** post-hıc $\cong$ ann-Whitney $U$ test (adjusted $P$-value $0.3 / 3=0.017)$.

Figure 1: (A,C,D,F) Standardizer. . nıュoposterior ankle Méary radiographic view to measure the hindfoot deformity. Hindınt axis with respect to the ground ( $\gamma$ angle: valgus $\leq 80$ degrees; varus $\geq 95$ degr $\_$) and the intra-articular ankle varus or valgus alignment (position of the talus with respec to the axis of the tibia: $\leq 80^{\circ}$ valgus; $\geq 100^{\circ}$ varus $) ;^{12,19}(\mathrm{~B}, \mathrm{E})$ Standardized weight-bearing lateral foot (and ankle) radiographic view to measure the midfoot deformity as the talar $/ 1^{\text {st }}$ metatarsal angle $\left(\beta 1\right.$ angle: $\leq 170^{\circ}$ high arch (cavus); $\geq$ $190^{\circ}$ low arch (planus)) and medial longitudinal arch deformation as the Djian-Annonier angle ( $\beta 2$ angle: $\leq 115^{\circ}$ high $\operatorname{arch}$ (cavus); $\geq 130^{\circ}$ low arch (planus)). Fig 1 A,B,C are foot and ankle deformities associated with the planus OA group; D,E,F, associated with the cavus OA group. Fig. F shows the "zig-zag" deformity, as the subtalar joint goes in the opposite direction (valgus) of the tibiotalar deformity (varus). 
Figure 2: Inter-segment centers were defined according to an adapted version of Rizzoli's foot model (Leardini et al. 2007) developed by Deschamps et al. (2017) (IOR-4Segmentmodel 1). Marker names: upper ridge of the posterior surface of the calcaneus (FC); peroneal tubercle (FPT); sustentaculum tali (FST); virtual cuboid marker (FCub), tuberosity of the navicular bone (FNT); $1^{\text {st }}, 2^{\text {nd }}$ and $5^{\text {th }}$ metatarsal base (FMB, SMB, FMT) $; 1^{\text {st }}, 2^{\text {nd }}$ and $5^{\text {th }}$ metatarsal head (FM1, FM2, FM5); PD6: distal dorso-medial aspect of the head of the proximal phalanx of the hallux; $1^{\text {st }}$ metatarso-phalangeal centor $($ FM1; midfoot-metatarsus center (SMB); calcaneus-midfoot center (ID)

Figure 3: Kinematic waveform representation $w^{+}{ }^{+1}+1$ standard deviation cloud for the intrinsic foot joints: Sha-Cal: Shank-Calcar eu. Cal-Mid: Calcaneus-Midfoot; Mid-Met: Midfoot-Metatarsus; 1st Metatarso-Phá 1 st Metatarso-Phalangeal joint. Cavus OA group (blue), Neutral OA group (green) anc Planus OA (purple); DF: dorsiflexion; PF: plantar

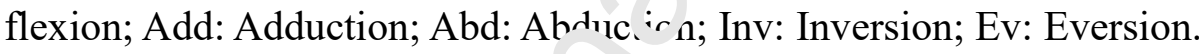

Figure 4: Kinetic between-y.np comparison of inter-segmental Shank-Calcaneus moments (Mx \& My) during th stance phase of gait. Cavus OA group (blue), Neutral OA group (green) and Planus OA group (purple); Sha-Cal: Shank-Calcaneus; $\boldsymbol{A}-\boldsymbol{C , G - I}$ : Mean kinetic trajectories with their respective standard deviation clouds. D-F, J-L: SPM results: $\operatorname{SPM}\{t\}$ curve is the trajectory of the post-hoc 2-sample t-test. Conceptually, an SPM post-hoc 2-sample t-test is similar to the calculation and interpretation of a scalar post-hoc 2-sample ttest at each instant of time. Where the SPM $\{\mathrm{t}\}$ curve exceeds the critical threshold (red dotted line in graphs D-F \& J-L) at one or multiple time nodes, this area is shaded in gray and a 
significant difference is present between the corresponding moment curves in the graph above.

Figure 5: Kinetic between-group comparison of 3D angle $\alpha_{\mathrm{M} \omega}$ of the Shank-Calcaneus (ShaCal) and Calcaneus-Midfoot (Cal-Mid) joints during the stance phase. Cavus OA group (blue), Neutral OA group (green) and Planus OA group (purple); Sha-Cal: Shank-Calcaneus; When the $3 \mathrm{D}$ angle $\alpha_{\mathrm{M} \omega}$ is $<60^{\circ}$ or $>120^{\circ}$, the moment mainly drives the joint, with, respectively, propulsion $(\mathbf{P})$ or resistance $(\mathbf{R})$. When the $3 \mathrm{\Gamma}$ a. $\mathrm{ale}_{\mathrm{M} \omega} \alpha_{\mathrm{M}}$ is between $60^{\circ}$ and $120^{\circ}$, the moment mainly stabilizes the joint (S); $\boldsymbol{A}-\boldsymbol{C},(-\boldsymbol{I}$ : : Mean kinetic trajectories with

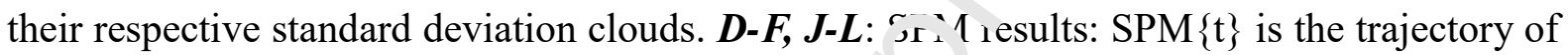
the post-hoc 2-sample t-test. Conceptually, an SPM post-1oc 2-sample t-test is similar to the calculation and interpretation of a scalar pc.t-huc 2-sample t-test at each instant of time. Where the SPM $\{$ t $\}$ curve exceeds the crits 1 threshold (red dotted line in graphs D-F \& J-L) at one or multiple time nodes, this art. is shaded in gray and a significant difference is present between the correspondirg in angle $\alpha_{\mathrm{M} \omega}$ curves in the graph above. 


\section{REFERENCES}

1. Barton T, Lintz F, Winson I. Biomechanical changes associated with the osteoarthritic, arthrodesed, and prosthetic ankle joint. Foot Ankle Surg. 2011;17(2):52-57. doi:10.1016/j.fas.2011.01.010.

2. Bruckner J. Variations in the Human Subtalar Joint. J Orthop Sport Phys Ther. 1987;8(10):489-494. doi:10.2519/jospt.1987.8.10.489.

3. Buldt AK, Allan JJ, Landorf KB, Menz HB. The relation h1 between foot posture and plantar pressure during walking in adults: A system ^tıc review. Gait Posture. 2018;62(July 2017):56-67. doi:10.1016/j.gaitpost ¿`ج18.02.026.

4. Buldt AK, Forghany S, Landorf KB, Levinger P, : Yurley GS, Menz HB. Foot posture is associated with plantar pressure durir $g_{s}{ }^{i+}$. A comparison of normal, planus and cavus feet. Gait Posture. 2018;62, Mrrch):235-240. doi:10.1016/j.gaitpost.2018.03.6ㄱ.

5. Buldt AK, Levinger P, Mur'sy 's, Menz HB, Nester CJ, Landorf KB. Foot posture is associated with kinemai, s or the foot during gait: A comparison of normal, planus and cavus feet. Gait Postu, 2015;42(1):42-48. doi:10.1016/j.gaitpost.2015.03.004.

6. Buldt AK, Murlt, Gs, Butterworth P, Levinger P, Menz HB, Landorf KB. The relationship between foot posture and lower limb kinematics during walking: A systematic review. Gait Posture. 2013;38(3):363-372. doi:10.1016/j.gaitpost.2013.01.010.

7. Deleu P-A, Chèze L, Dumas R, et al. Intrinsic foot joints adapt a stabilized-resistive configuration during the stance phase. J Foot Ankle Res. 2020;13(1):13. doi:10.1186/s13047-020-0381-7.

8. Deleu PA, Besse JL, Naaim A, et al. Change in gait biomechanics after total ankle 
replacement and ankle arthrodesis: a systematic review and meta-analysis. Clin Biomech. 2020;73(January):213-225. doi:10.1016/j.clinbiomech.2020.01.015.

9. Deschamps K, Eerdekens M, Desmet D, Matricali GA, Wuite S, Staes F. Estimation of foot joint kinetics in three and four segment foot models using an existing proportionality scheme: Application in paediatric barefoot walking. J Biomech. 2017;61:168-175. doi:10.1016/j.jbiomech.2017.07.017.

10. Djian A, Annonier C, Denis A, Baudoin P. [Radiopodometry (principles and results)]. J Radiol Electrol Med Nucl. 1968;49(10):769-772.

11. Drayer-Verhagen F. Arthritis of the subtalar joint as soc ted with sustentaculum tali facet configuration. J Anat. 1993;183 ( Pt 3:631 ho:

12. Dumas R, Cheze L. Hip and knee joints are $m$ re tabilized than driven during the stance phase of gait: An analysis of the $3 \mathrm{~L}$ ar gle between joint moment and joint angular velocity. Gait Posture. 2C ’8 '_8(2):243-250.

doi:10.1016/j.gaitpost.2007.12.เ`?3

13. Eerdekens M, Deschamps $V$ V'ite S, Matricali G. The Biomechanical Behavior of Distal Foot Joints in Pai 'nts with Isolated, End-Stage Tibiotalar Osteoarthritis Is Not Altered Following Tib: ^^ dlar Fusion. J Clin Med. 2020;9(8):2594. doi:10.3390/jcm;'ๆ $<594$.

14. Eerdekens M, Staes F, Matricali GA, Deschamps K. Clinical Applicability of an Existing Proportionality Scheme in Three-Segment Kinetic Foot Models. Ann Biomed Eng. 2020;48(1):247-257. doi:10.1007/s10439-019-02344-8.

15. Friston KJ, Holmes AP, Worsley KJ, Poline J-P, Frith CD, Frackowiak RSJ. Statistical parametric maps in functional imaging: A general linear approach. Hum Brain Mapp. 1994;2(4):189-210. doi:10.1002/hbm.460020402.

16. Hintermann B, Knupp M, Barg A. Peritalar Instability. FOOT ANKLE Int. 
2012;33(5):450-454. doi:10.3113/FAI.2012.0450.

17. Jung M-H, Choi BY, Lee JY, et al. Types of subtalar joint facets. Surg Radiol Anat. 2015;37(6):629-638. doi:10.1007/s00276-015-1472-1.

18. Kessler SE, Rainbow MJ, Lichtwark GA, et al. A Direct Comparison of Biplanar Videoradiography and Optical Motion Capture for Foot and Ankle Kinematics. Front Bioeng Biotechnol. 2019;7(August):1-10. doi:10.3389/fbioe.2019.00199.

19. Khazzam M, Long JT, Marks RM, Harris GF. Preoperative gait characterization of patients with ankle arthrosis. Gait Posture. 2006;24(1):85-9: doi:10.1016/j.gaitpost.2005.07.006.

20. Knupp M. The Use of Osteotomies in the Treatmen. of Asymmetric Ankle Joint Arthritis. Foot Ankle Int. 2017;38(2):220-229 do. 10.1177/1071100716679190.

21. Knupp M, Hintermann B. Treatment of $A_{\llcorner} \cdot$ m m metric Arthritis of the Ankle Joint With Supramalleolar Osteotomies. FO('T .NKLE Int. 2012;33(3):250-252. doi:10.3113/FAI.2012.0250.

22. Knupp M, Stufkens S a S, mn .2 rgen CJ, et al. Effect of supramalleolar varus and valgus deformities on thı tibıtalar joint: a cadaveric study. Foot ankle Int. 2011;32(6):609-615 uii・10.3113/FAI.2011.0609.

23. Krahenbuhl N, Hi rn-Lang T, Hintermann B, Knupp M. The subtalar joint: a complex mechanism. EFORT OPEN Rev. 2017;2(7):309-316. doi:10.1302/20585241.2.160050.

24. Krause FG, Di Silvestro M, Penner MJ, et al. Inter- and intraobserver reliability of the COFAS end-stage ankle arthritis classification system. Foot Ankle Int. 2010;31(2):103-108. doi:10.3113/FAI.2010.0103.

25. Kruger KM, Graf A, Flanagan A, et al. Segmental foot and ankle kinematic differences between rectus, planus, and cavus foot types. J Biomech. 2019. 
doi:10.1016/j.jbiomech.2019.07.032.

26. Leardini a, Benedetti MG, Berti L, Bettinelli D, Nativo R, Giannini S. Rear-foot, midfoot and fore-foot motion during the stance phase of gait. Gait Posture. 2007;25(3):453-462. doi:10.1016/j.gaitpost.2006.05.017.

27. Leardini A, Caravaggi P, Theologis T, Stebbins J. Multi-segment foot models and their use in clinical populations. Gait Posture. 2019;69:50-59. doi:10.1016/j.gaitpost.2019.01.022.

28. Leardini A, O’Connor JJ, Giannini S. Biomechanics of the nt tural, arthritic, and

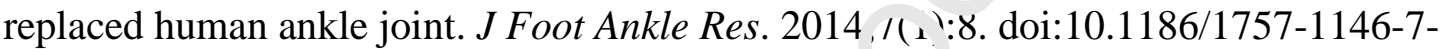
8.

29. Legnani G, Casolo F, Righettini P, Zappa B. f. hu nogeneous matrix approach to 3D kinematics and dynamics — I. Theory. $\|_{c} \cdot h$ Mach Theory. 1996;31(5):573-587. doi:10.1016/0094-114X(95)0010 D

30. Meary R, Filipe G, Aubriot JH, Inmeno B. [Functional study of a double arthrodesis of the foot]. Rev Chir Orthrn $K$ ? aratrice Appar Mot. 1977;63(4):345-359.

31. Murley GS, Landorf KE, Menz HB, Bird AR. Effect of foot posture, foot orthoses and footwear on lower limi r.uscle activity during walking and running: A systematic review. Gait Pos.'re. 2009;29(2):172-187. doi:10.1016/j.gaitpost.2008.08.015.

32. Pataky TC. Generalized n-dimensional biomechanical field analysis using statistical parametric mapping. J Biomech. 2010;43(10):1976-1982.

doi:10.1016/j.jbiomech.2010.03.008.

33. Pataky TC. One-dimensional statistical parametric mapping in Python. Comput Methods Biomech Biomed Engin. 2012;15(3):295-301. doi:10.1080/10255842.2010.527837.

34. Queen R. Directing clinical care using lower extremity biomechanics in patients with 
ankle osteoarthritis and ankle arthroplasty. J Orthop Res. 2017;35(11):2345-2355. doi:10.1002/jor.23609.

35. Rouhani H, Favre J, Crevoisier X, Aminian K. A wearable system for multi-segment foot kinetics measurement. J Biomech. 2014;47(7):1704-1711.

doi:10.1016/j.jbiomech.2014.02.027.

36. Saraswat P, MacWilliams BA, Davis RB, D'Astous JL. Kinematics and kinetics of normal and planovalgus feet during walking. Gait Posture. 2014;39(1):339-345. doi:10.1016/j.gaitpost.2013.08.003.

37. Schmitt D, Vap A, Queen RM. Effect of end-stage '،1p, 'knee, and ankle osteoarthritis on walking mechanics. Gait Posture. 2015;42(3)•3,23-379. doi:10.1016/j.gaitpost.2015.07.005.

38. Valderrabano V, Nigg BM, von Tschar e $e_{\imath}$ V Stefanyshyn DJ, Goepfert B, Hintermann B. Gait analysis in aı. -1e osteoarthritis and total ankle replacement. Clin Biomech. 2007;22(8):894-904. a i:10.1016/j.clinbiomech.2007.05.003. 


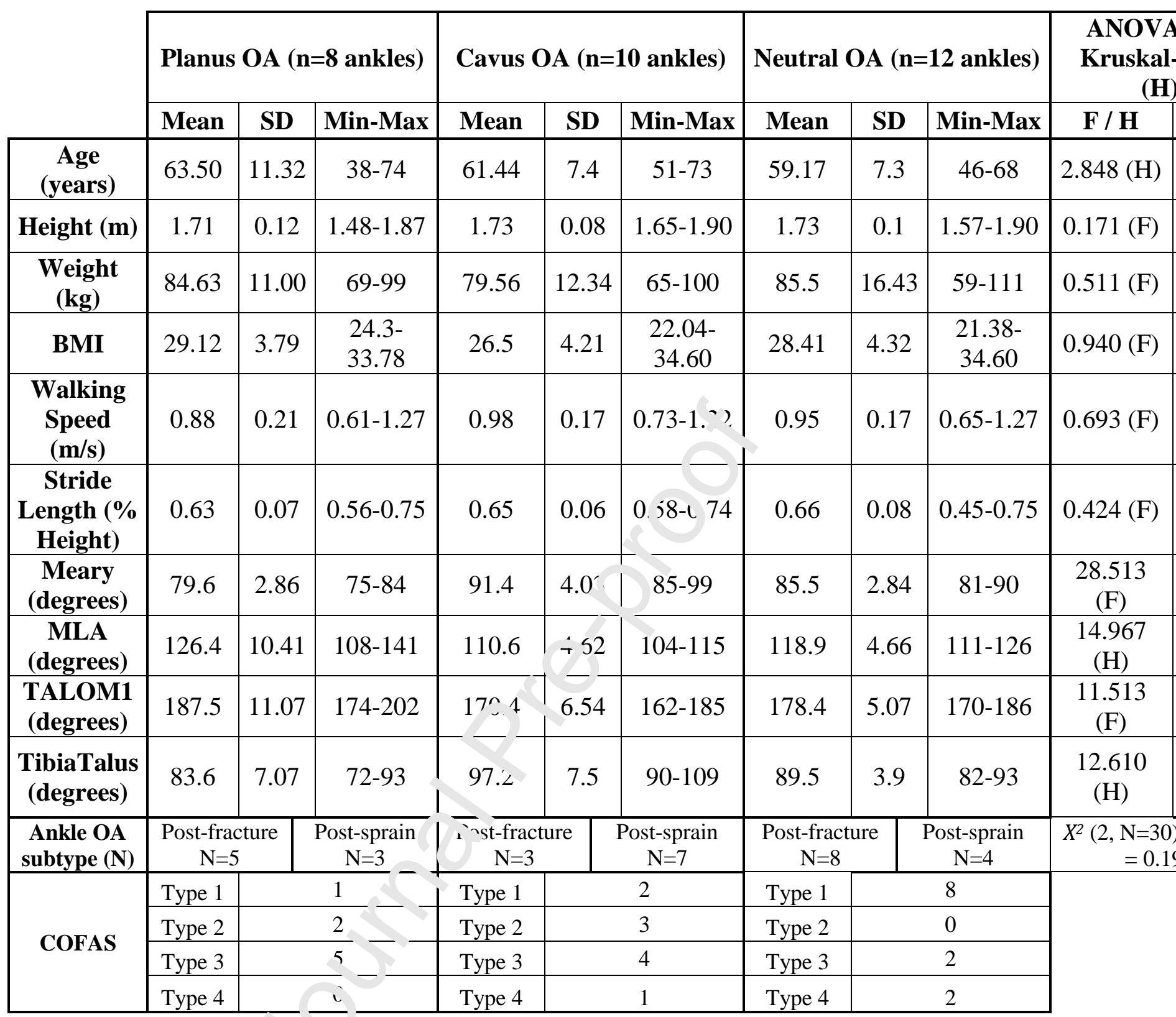

Table 1: Demographic, spatio- mpural and radiographic data for the three patient groups: post-traumatic ankle osteoarthritis associated with pla us foot deformity (Planus OA), with cavus foot deformity (Cavus OA), and without foot deformity (Neutraı OA). Abbreviations: COFAS: Canadian Orthopaedic Foot \& Ankle Society classification system for ankle osteoarthritis; MLA: medial longitudinal arch; SD: standard deviation; BMI: body mass index; N/A: not applicable; N.S.: not significant. Statistics: Depending on the distribution of the demographic and spatio-temporal data, 1-way ANOVA (normal distribution) ${ }^{\mathrm{a}}$ or Kruskal-Wallis test (non-normal distribution) ${ }^{\mathrm{b}}$ were used to assess statistical differences for each variable between the three groups. ${ }^{\mathrm{c}} \mathrm{X}^{2}$ Extended Chi-square test ; *Gabriel's post-hoc test (adjusted $P$-value $0.3 / 3=0.017$ ); ** post-hoc Mann-Whitney U test (adjusted $P$-value $0.3 / 3=0.017)$. 


\section{HIGHLIGHTS}

- Malalignment in ankle osteoarthritis does affect foot mechanics during gait

- Frontal and transverse plane kinetics should be assessed in ankle osteoarthritis

- Calcaneus-Midfoot and Midfoot-Metatarsus joints are affected by malalignment in ankle osteoarthritis

- Cavus osteoarthritic group compensate ankle varus deformity through MidfootMetatarsus joint 


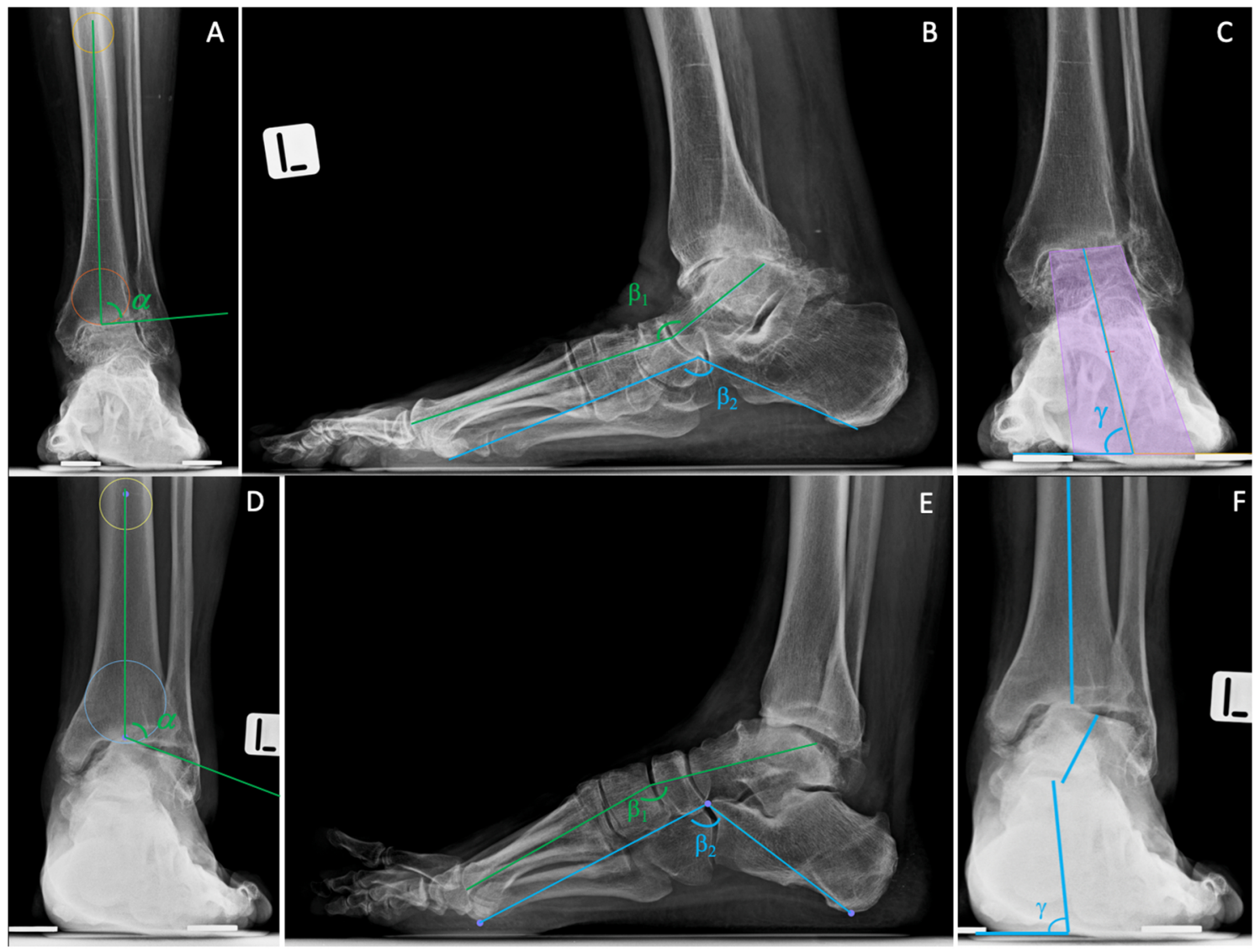

Figure 1 


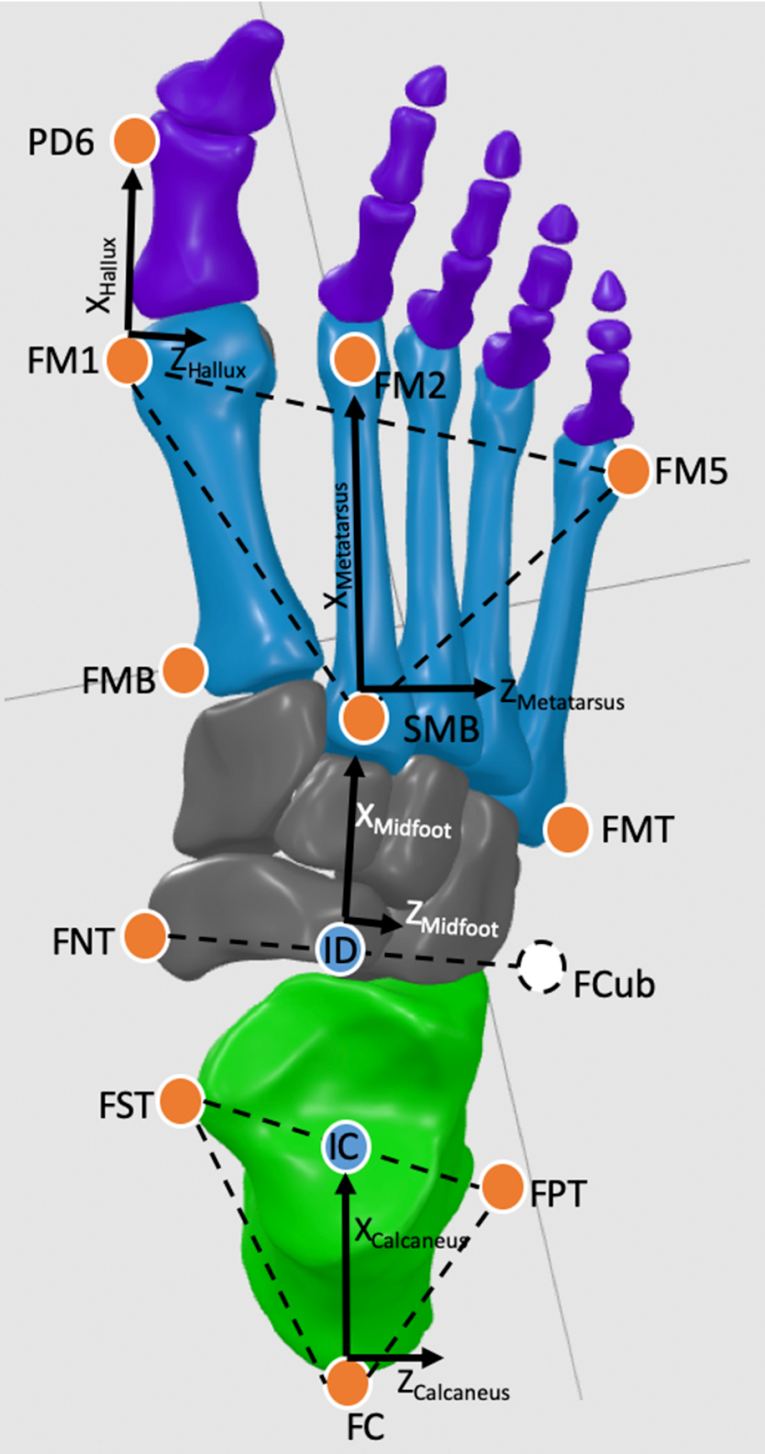

Figure 2 

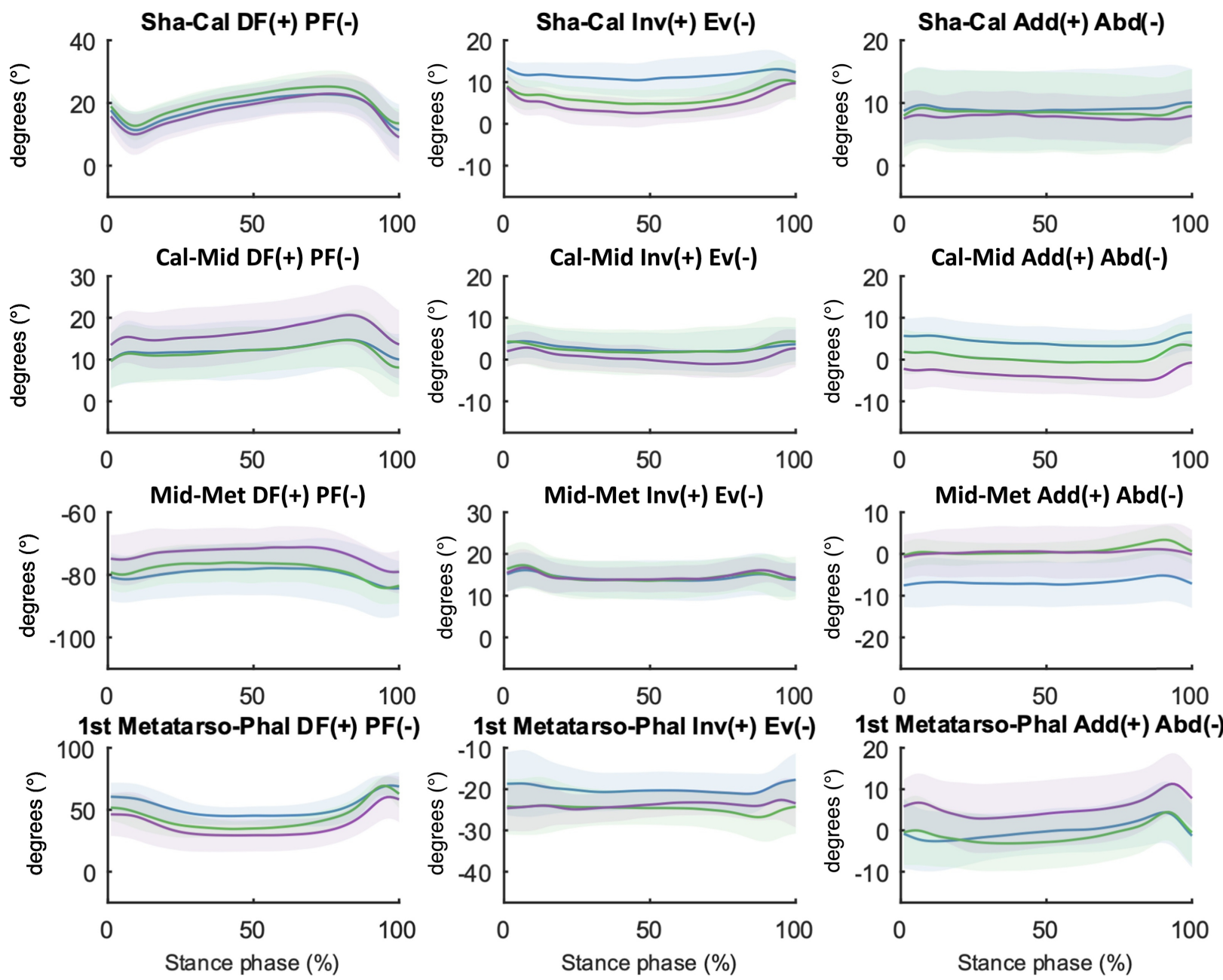

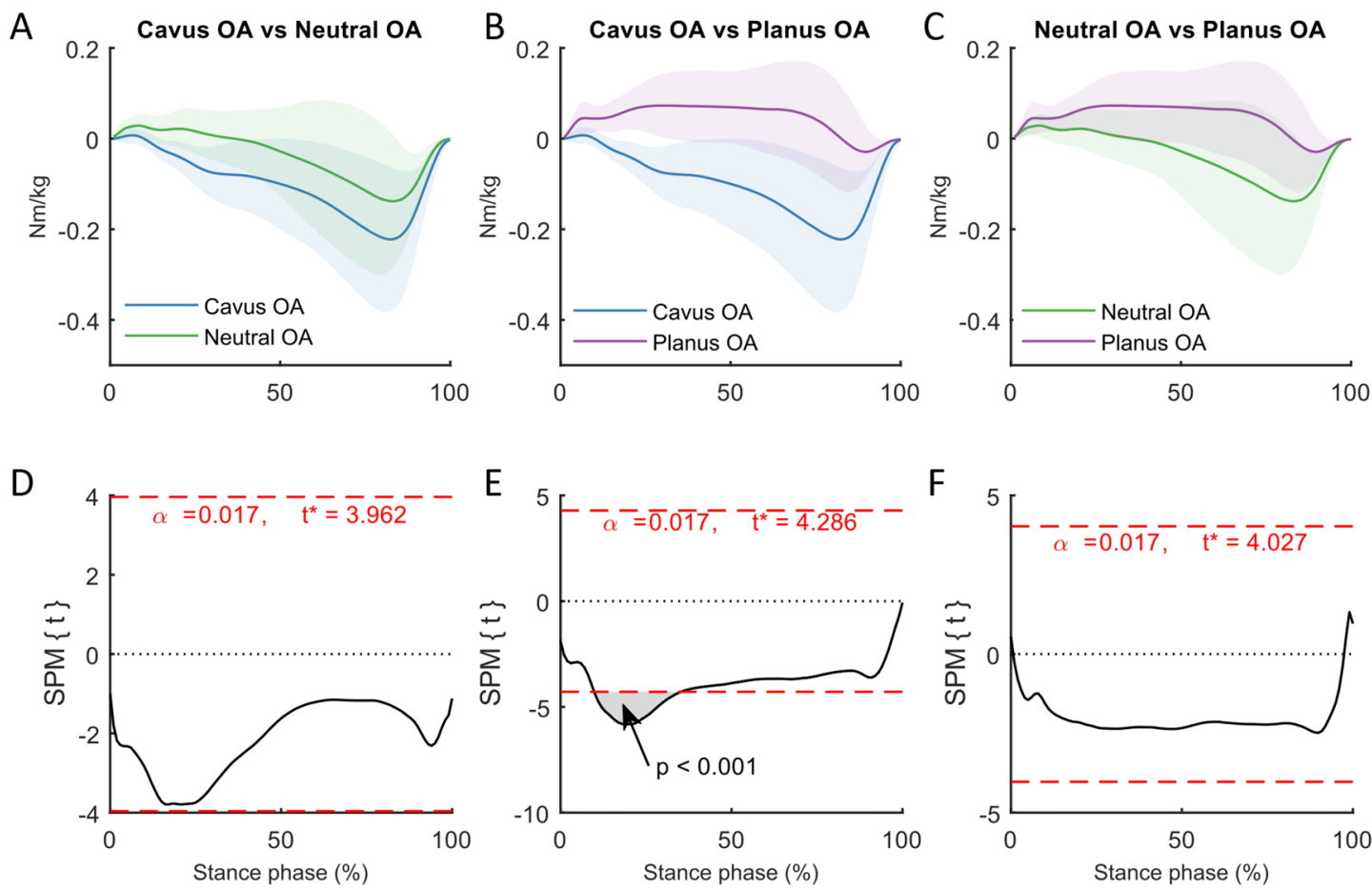

Sha-Cal My Add(+) Abd(-)
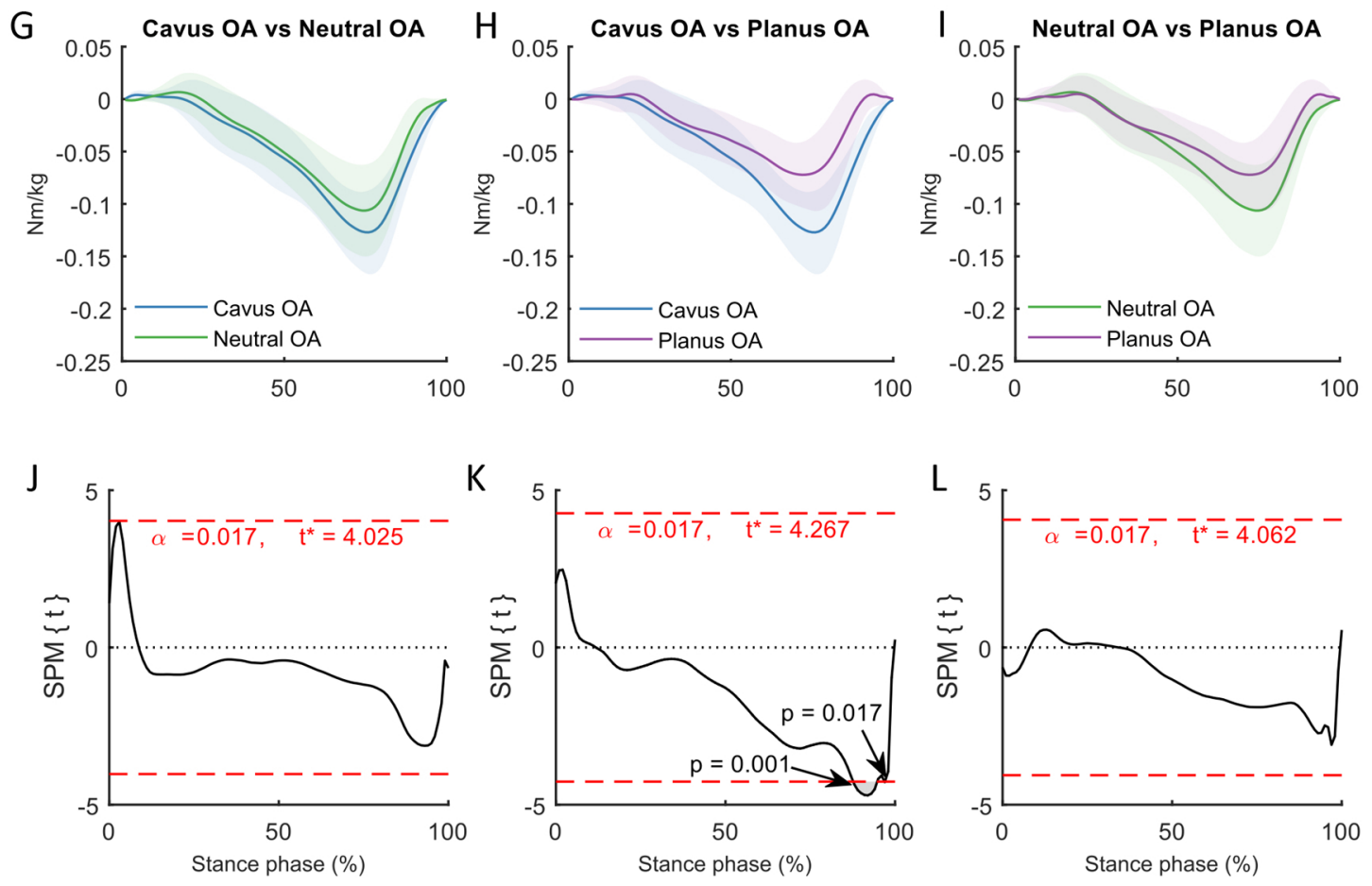


\section{Sha-Cal Alpha}
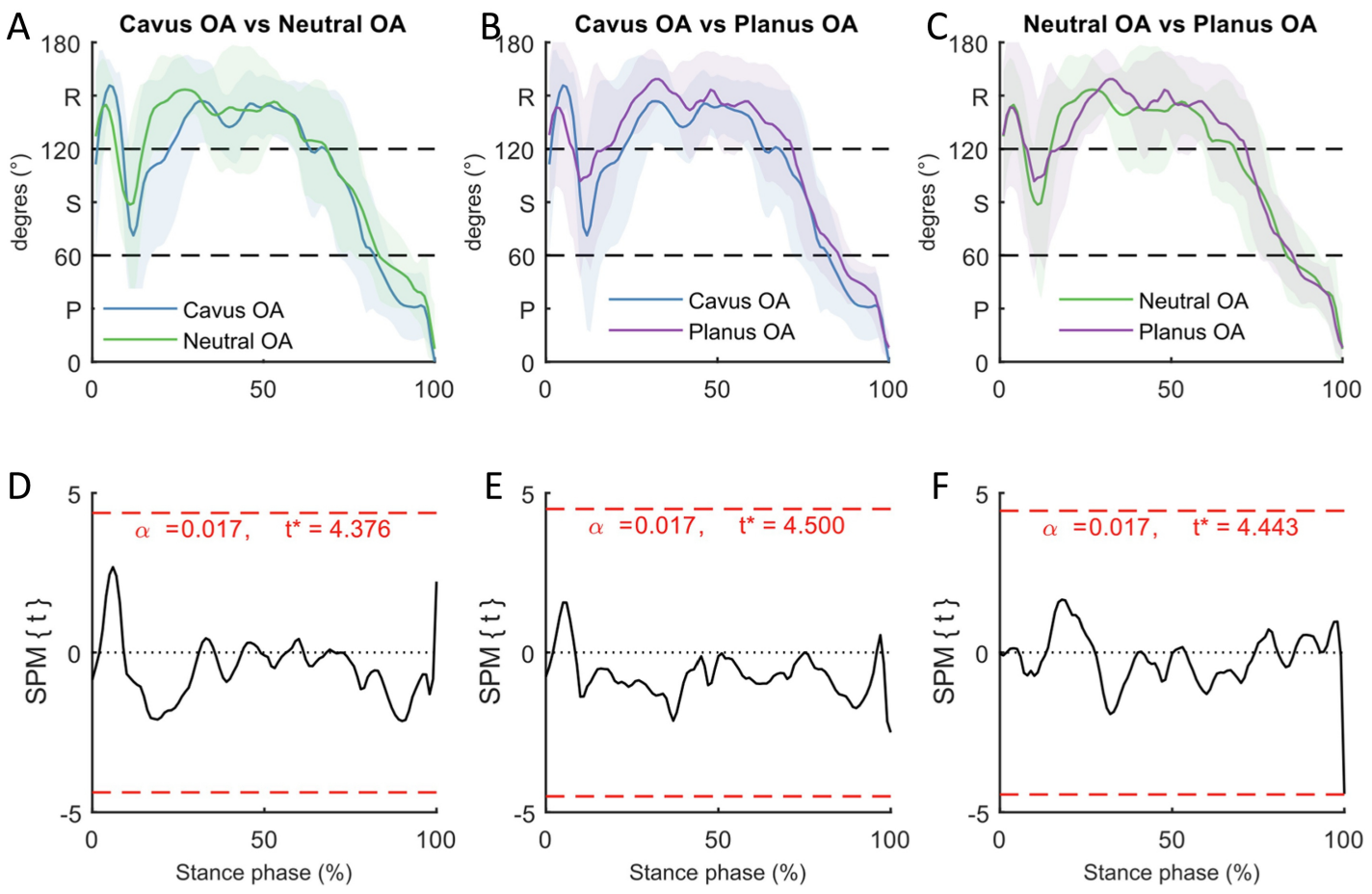

Cal-Mid Alpha

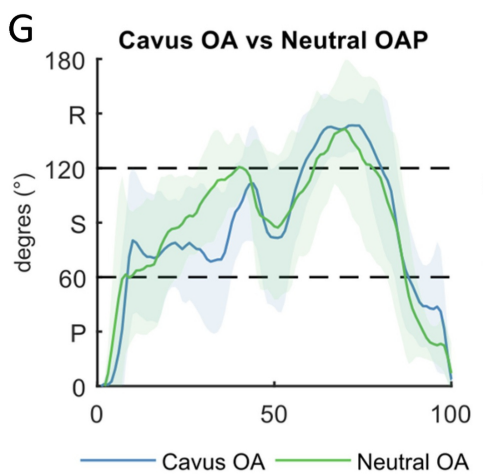

$J$

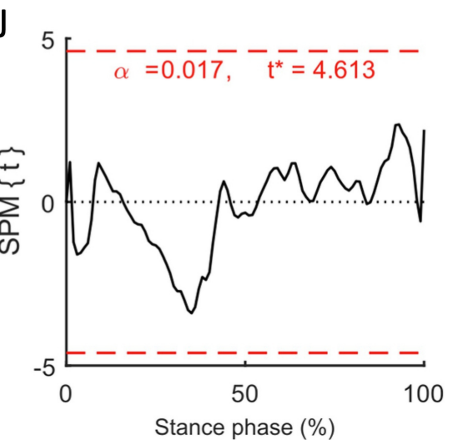

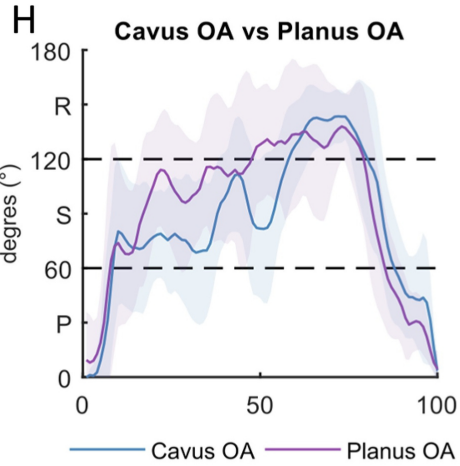

K

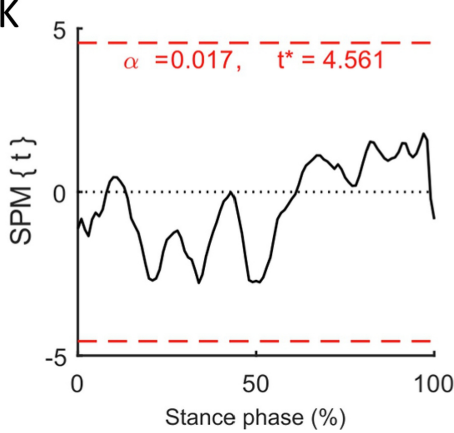

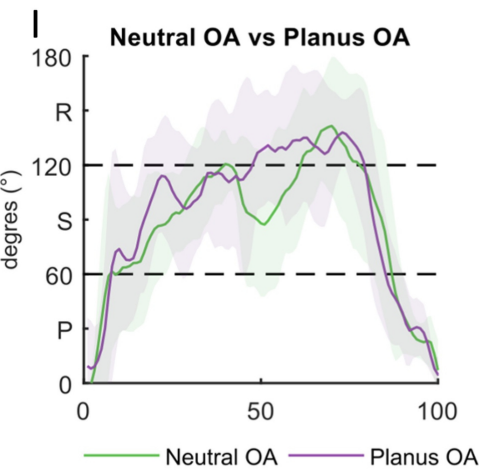

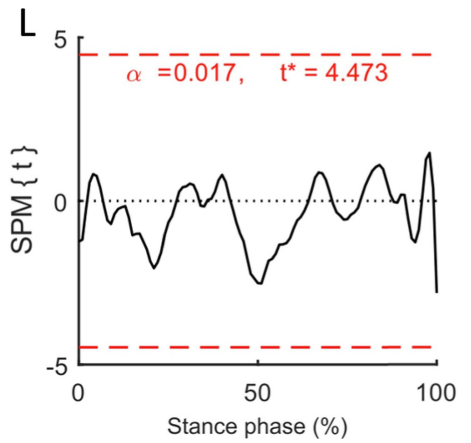

